\title{
Barriers for industrial implementation of in-process monitoring of weld penetration for quality control
}

\author{
Anna Ericson Öberg ${ }^{1,2} \cdot$ Fredrik Sikström ${ }^{3}$
}

Received: 19 April 2016 / Published online: 5 January 2017

(C) The Author(s) 2017. This article is published with open access at Springerlink.com

\begin{abstract}
The research conducted sheds a light on the question why robust in-process monitoring and adaptive control are not fully implemented in the welding industry. In the research project FaRoMonitA, the possibilities to monitor the weld quality during welding have been investigated. Research conducted in this area has merely focused on technical issues investigated in a laboratory environment. To advance the research front and release some barriers related to industrial acceptance, the studies conducted in this paper have been both quantitative and qualitative in form of experiments combined with an interview study. The quality property weld penetration depth was chosen for in-process monitoring to evaluate the industrial relevance and applicability. A guaranteed weld penetration depth is critical for companies producing parts influenced by fatigue. The parts studied were fillet welds produced by gas metal arc welding. The experiments show that there is a relationship between final penetration depth and monitored arc voltage signals and images captured by CMOS vision and infrared cameras during welding. There are still technical issues to be solved to reach a robust solution. The interview study indicates that soft issues, like competence and financial aspects, are just as critical.
\end{abstract}

\footnotetext{
Anna Ericson Öberg

anna.ericson.oberg@volvo.com

1 Volvo Construction Equipment, Box 303, SE 671 27, Arvika, Sweden

2 Chalmers University of Technology, Gothenburg, Sweden

3 University West, Trollhättan, Sweden
}

Keywords Process monitoring · Gas metal arc welding . Fillet weld · Weld penetration - Quality assurance . Manufacturing $\cdot$ Non-destructive testing

\section{Introduction}

The research conducted highlights some barriers that prevent companies from implementing in-process monitoring and control in order to assure the weld quality. The chosen quality aspect to monitor is weld penetration depth $(i$ in Fig. 1) in fillet welds produced by gas metal arc welding (GMAW) [26].

Weld penetration is highly connected to fatigue life [5], and consequently, it is important for companies producing parts influenced by fatigue to be able to assure a sufficient weld penetration depth. With a known penetration depth, the weld throat thickness ( $a$ in Fig. 1) can in some cases be reduced [4], thereby increasing productivity and reducing cost. Previous research conducted on in-process monitoring of the weld quality has merely been performed in a laboratory environment, focusing on technical issues and monitoring very rough defects and properties. To get a broader understanding of the barriers preventing implementation of the technical solutions, the experiments were complemented with an interview study. By combining quantitative experimental tests with these qualitative interviews, not only technical barriers were found but also soft ones like competence and financial aspects. This gives a more holistic understanding of the issues.

The Swedish Knowledge Foundation-funded research project FaRoMonitA investigated the possibilities to monitor the weld quality during welding by analyzing the 
electrical signals in form of arc voltage as well as images captured by CMOS vision and infrared cameras. In addition to the technical experiments, the participating companies were interviewed to find factors preventing them from using possibilities to utilize in-process monitoring of weld quality. The participating companies are large manufacturing companies where welding is considered an important process with a yearly production volume in the range from 100 up to 20,000 welded parts. The companies are active in construction equipment (company A), energy (company B) and aerospace (company $\mathrm{C}$ ). The cost of the manufactured products ranges from 10,000 SEK to several millions.

This paper sheds light on the question why robust inprocess monitoring and adaptive control are not yet generally implemented in the welding industry. There are still technical issues to be solved but the soft issues are just as critical. The interview study indicates mainly two soft areas to consider: competence and financial aspects. Competence was mentioned as a barrier by all the three companies. The cost associated with weld defects is not clear, and monitoring equipment is handled in the investment process, where a profitable business case needs to be formulated. By identifying these issues, the research has contributed with building blocks towards implemented in-process monitoring of weld quality.

The paper will first introduce the theories behind penetration depth and suitable monitoring technologies. After an overview of the chosen experimental set-up used to collect empirical data, the experimental findings and the findings from the interview study are presented. The paper concludes with a discussion and ideas for future research.

\section{Theoretical framework}

The theoretical framework presents theories on weld penetration depth and gives an overview of performed research within the area of in-process monitoring of weld quality.

\subsection{Weld penetration depth}

The arc welding process is very complex. Numerous parameters influence the result, such as arc voltage, welding current, joint gap size, filler wire stick-out, shield gas flow etc. The parameters are not only influential by themselves but are also interdependent. The quality of the weld seam is typically depending on its outer appearance as well as presence of internal defects. This is commonly described in weld standards, such as in $[23,24]$. This study focuses on fillet welds of 12-mm structural steel plates and the weld penetration depth due to its high relevance to fatigue life. The penetration depth, $i$, describes how deep the plates have been bonded as shown in Fig. 1.

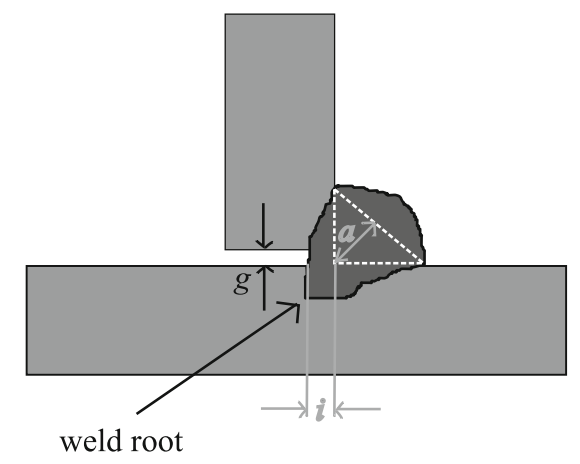

Fig. 1 Illustration of two plates joined by a fillet weld

Incomplete penetration reduces the load carrying cross section and corresponds geometrically to a crack [16]. Studies show corresponding fluctuations observed in the fatigue life with change in weld penetrations, see e. g. [5] by Deshmukh et al. When the root-side of a fatigue-loaded structure is critical, the weld penetration depth influences the fatigue life. Research by Dahle et al. [4] shows that for certain fillet welds, the penetration depth $i$ has twice as much influence on the fatigue life as the throat thickness $a$.

For most welds, the penetration depth is not visible after welding and therefore, difficult to inspect and control. A common procedure is to use destructive testing on test samples. The test procedure used at the company A consists of four steps: welding of test pieces, marking and preparation, pressing the parts apart and finally, measuring the penetration in the flange and web plate using caliper as shown in Fig. 2.

There are many downsides with only using destructive testing, e.g. lack of possibility to test completed parts. The preferable solution should be to be able to predict the penetration depth already before or during welding. Hammersberg and Olsson [8] have performed a study on proactive control of weld dimensions to achieve this. A process window for robotized GMAW that simultaneously fulfils all requirements on fillet weld bead dimensions (regarding thickness, penetration and toe radii at the bead/base material transition) for a particular welding case was identified and studied by multi-parameter regression modelling. No simple relationships between control parameters and weld bead dimensions were found for this welding scenario, requiring a multi-parameter approach. The noise level in the system was high (process and measurement noise) reinforcing the need for a structured approach. Even though the pre-process control is very promising, an option to utilize in-process monitoring of penetration depth is still attractive.

A possibility to guarantee a certain penetration depth would greatly affect the design and production of welded structures. The current destructive testing is expensive and gives limited knowledge of the current production process; 
Fig. 2 Welded test piece is pressed apart by vertical force (left). Penetration depth is measured in web (middle) and in flange (right) [15]
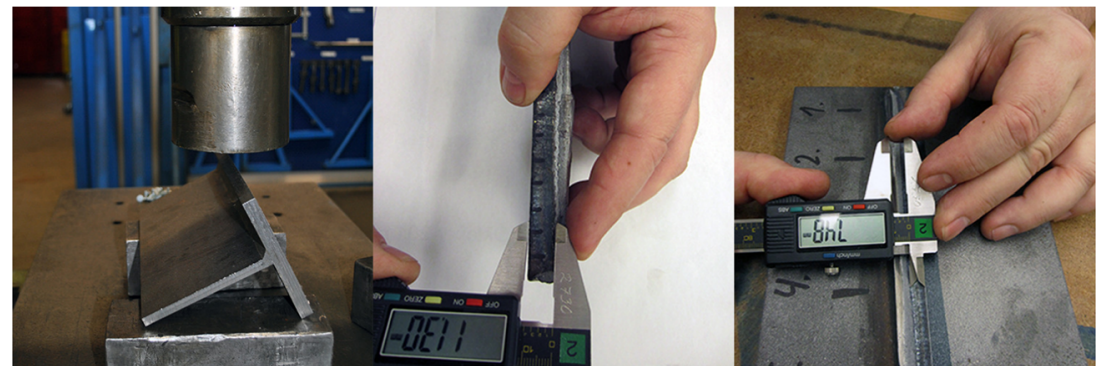

it is rather a snapshot of the result. The testing is timeconsuming, and the result is not instant, but delayed. The non-destructive testing commonly used today, such as ultrasonic testing, is also not always suitable for this type of weld seam due to e.g. accessibility and joint appearance. This uncertainty about the weld result affects the productivity. The different functions within the manufacturing industry are handling the uncertain weld result by adding safety margins in each step-leading to increased cost [6]. The uncertainty also means that research results towards lighter products cannot be fully implemented. That is because a development towards thinner plates and a smaller weld throat thickness creates an even more sensitive process with a smaller process window. The consequences of too shallow penetration depths are serious and could lead to breakdowns. If in-process monitoring could be used to guarantee the weld penetration depth, that would lead to reduced safety margins and possibility to implement lighter design solutions, hence increasing productivity.

\subsection{In-process monitoring}

Monitoring during welding could be one solution for reducing cost of poor quality by identifying when there is a risk of deviations from desired performance. Today, the operator needs to be very skilled to distinguish good welds from bad, especially since all properties are not easily visible. A monitoring system would ease the workload and take over some of the decision-making from the operator. This could influence the need of modified workforce profile.

Research within this area for gas tungsten arc welding (GTAW), GMAW and shielded metal arc welding (SMAW) has taken different paths as shown in Table 1. Some studies have been focused on weld properties; others on weld defects, or a combination. Different types of weld joints like overlap welds, butt welds, bead on plate and fillet welds are covered as well as diverse monitoring methods such as electrical signals, vision, infrared sensors or audio sensing.

Li et al. [11] describe a vision inspection system with structured light. The system has been used on butt welds and can detect both dimensioning properties like groove width and filling depth as well as weld defects like displacement, misalignment and undercut. Schreiber et al. [17] also investigate butt welds, using a camera and a stroboscope. The quality is learned from a couple of training seams. During monitoring, the current work is compared to the reference values achieved by the training seams. This system could monitor seam position and width as well as light distribution. Simpson [19] also uses reference welds for comparison to identify defects. The research was however based on signature images of the electrical parameters and was performed on fillet welds. Lv et al. [13] base their system on the relationship between sag depression and penetration status, and state that it is possible to achieve control of weld penetration based on an audio sensing system.

The equipment should be able to discover the weld discontinuities immediately in a harsh environment including high temperatures, bright arc plasma emissions, fumes and spatter. The research in the field has merely performed tests in a laboratory environment. In his review paper, Wang [25] concludes that more work still needs to be done to apply the research results in industry for improved welding automation and intelligence. The issues reported are to a large extent technical, such as light reflections [17], effective processing algorithms [25] and robust sensors [25]. In case of electrical signals, the advantages are robustness and non-intrusive sensing, but the signals can be difficult to interpret [19]. These examples visualize the need for a stronger connection to an industrial context. This paper takes a broader, both technical and organizational perspective, investigating reasons why robust in-process monitoring and adaptive control of penetration in fillet welds are not yet fully implemented in the industry.

\section{Experimental procedure}

The case study described in this paper includes two parts: firstly, the technical experiment of estimating penetration depth by first estimating gap size using recorded arc voltage signals and camera sequences, and secondly, an interview study. The empirical experiment identifies technical issues that need to be addressed to implement in-process monitoring in the industry. The interview study offers a unique opportunity to get an insight in how the industry experiences 
Table 1 Overview of research focus concerning monitoring of weld quality

\begin{tabular}{|c|c|c|c|}
\hline Focus & Welding method & Joint type & Monitoring method \\
\hline Properties & GTAW & Overlap weld & Electrical signals \\
\hline Simpson [20] & Lv et al. [13] & Simpson [20] & Simpson [20] \\
\hline Lv et al. [13] & Lin et al. [12] & Simpson [18] & Simpson [19] \\
\hline Lin et al. [12] & Chandrasekhar et al. [3] & Butt weld & Simpson [18] \\
\hline Chandrasekhar et al. [3] & St. Weglowski [21] & Simpson [20] & Vision \\
\hline Defects & GMAW & Li et al. [11] & Lin et al. [12] \\
\hline Simpson [19] & Al-Habaibeh and Parkin [1] & Lin et al. [12] & Schreiber et al. [17] \\
\hline Simpson [18] & Simpson [20] & Lv et al. [13] & Li et al. [11] \\
\hline Al-Habaibeh and Parkin [1] & Simpson [19] & Al-Habaibeh and Parkin [1] & Infrared \\
\hline Fidali and Jamrozik [7] & Simpson [18] & Chandrasekhar et al. [3] & Al-Habaibeh and Parkin [1] \\
\hline Sumesh [22] & Schreiber et al. [17] & Schreiber et al. [17] & Chandrasekhar et al. [3] \\
\hline Combination & Li et al. [11] & Fidali and Jamrozik [7] & Fused vision and infrared \\
\hline Li et al. [11] & Cayo and Alfaro [2] & Sumesh [22] & Jamrozik [7] \\
\hline Schreiber et al. [17] & Zhiyong et al. [27] & Bead on plate & Audio \\
\hline Disturbances & Fidali and Jamrozik [7] & Cayo and Alfaro [2] & Lv et al. [13] \\
\hline Cayo and Alfaro [2] & SMAW & Zhiyong et al. [27] & Cayo and Alfaro [2] \\
\hline Zhiyong et al. [27] & Sumesh [22] & St. Weglowski [21] & Sumesh [22] \\
\hline \multirow[t]{3}{*}{ St. Weglowski [21] } & & Fillet weld & Spectrometer \\
\hline & & Simpson [19] & Zhiyong et al. [27] \\
\hline & & & St. Weglowski [21] \\
\hline
\end{tabular}

the possibility to use this type of in-process monitoring in quality assurance.

\subsection{Monitoring experiment}

Cruciform weld samples were produced from plates aligned to form four fillet-welded joints on each. The joints have zero gap sections alternated with equally spaced segments along the weld path with well-defined gaps in the form of arches with a maximum height $\leq 1 \mathrm{~mm}$. The arches start and end with zero gap sections where the plates were tack welded. Two situations occurred with this geometry: one with no weld on the opposite side and another with a weld on the opposite side. See Fig. 3 that showed one of the tack-welded samples.

The studied samples were welded using a typical industrial robot cell and a welding power source (Fronius VR7000CMT) with parameters set to achieve a weld throat

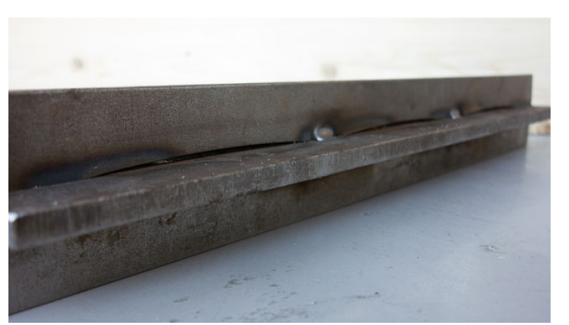

Fig. 3 Tack welded sample showing the cut arches and tack welds thickness of $5 \mathrm{~mm}$. The GMAW process mode used was spray arc. No joint tracking system was applied. The experiment was set-up to be representative of common production. The experimental details are summarized in Table 2.

Table 2 Experimental parameters

\begin{tabular}{ll}
\hline Parameter & Value \\
\hline Plate size & $590 \times 35 \mathrm{~mm}$ \\
Plate thickness & $12 \mathrm{~mm}$ \\
Steel type & S355 structural steel \\
Welding wire diameter & $1.2 \mathrm{~mm}$ \\
Welding wire type & Solid G3S/1 \\
Wire feed rate & $11.3 \mathrm{~m} / \mathrm{min}$ \\
Welding travel speed & $48 \mathrm{~cm} / \mathrm{min}$ \\
Shielding gas type & Mison-18 \\
Shielding gas flow & $201 / \mathrm{min}$ \\
Weaving amplitude & $3.2 \mathrm{~mm}$ \\
Weaving frequency & $2.76 \mathrm{~Hz}$ \\
Voltage & $26.5 \mathrm{~V}$ \\
Current & $351 \mathrm{~A}$ \\
Stick out & $15 \mathrm{~mm}$ \\
Torch angle between plates & $45^{\circ}$ \\
Torch angle forehand welding & $90^{\circ}$ \\
Aim & Centered in the corner
\end{tabular}


For the purpose of gap estimation, the arc voltage was measured, and two types of COMS cameras were observing the process. The electrical signal was acquired and recorded by the welding power source. A digital Butterworth low pass filter with a cut-off frequency chosen to attenuate the periodic disturbance from the weaving of the welding torch was used with the arc voltage signals and camera sequences to give a gap estimation that is more clearly disclosed.

A vision camera from Photonfocus (MV1-D1312 (IE)G2) and an IR camera from Xenics (Bobcat-640) were used to estimate the joint gap from the image sequence by feature extraction based on image binarization and projection transformation where the estimation data is fitted to the nominal joint geometry by solving the normal equation for a least square fit. The vision camera has a high dynamic range of $120 \mathrm{~dB}$ covering a very broad range of illumination to obtain geometrical information with a minimum loss of information. The spectral responsivity of this camera is in the range 200 to $1000 \mathrm{~nm}$. The IR camera has an InGaAs detector with a spectral responsivity in the range 900 to $1700 \mathrm{~nm}$. It is used in order to capture the geometrical boundary between solid and liquid metal. Both cameras have an active pixel sensor and global shutter technologies enabling high-speed imaging.

In a mirror rig, the two cameras look through a short-pass dichroic beam splitter to separate the spectral ranges of the cameras. The vision camera sees right through the mirror. The infrared camera is placed in a $90^{\circ}$ angle as shown in Fig. 4 and captures the reflected image. Additional optical filters have been used to suppress the irradiation from highly intense spectral peaks in the arc plasma.

Image registration has first been used to transform the cameras' image sequences into one coordinate system for image alignment. Image fusion has then been employed to combine information from the two images into a single

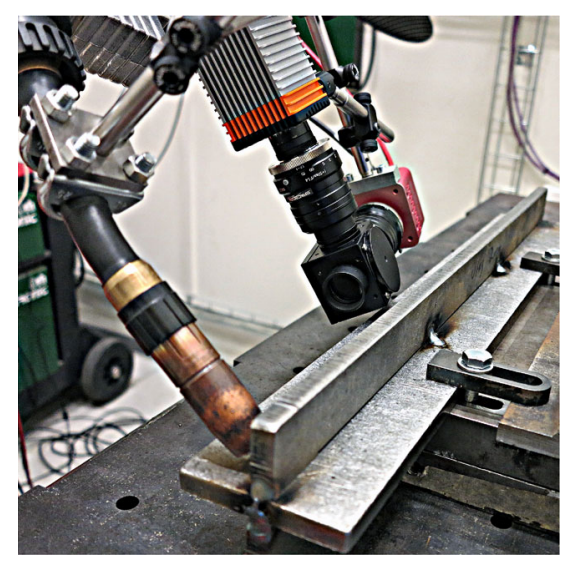

Fig. 4 Experimental set-up with the two cameras mounted on a mirror rig (the black cube) composite image. The purpose with the fusion was to enhance features (edges) that relate to the gap estimate. Principal component analysis-based image fusion has successfully been chosen for evaluation in this work [14].

\subsection{Interview study}

It was expected that not only technical barriers were present but also that soft issues were affecting the implementation rate of new technology at the companies. Therefore, an interview study was performed to understand the experienced barriers.

The interview study was performed at one site of each of the companies participating in the research project: construction equipment (company A), energy (company B) and aerospace (company $\mathrm{C}$ ). The companies are large manufacturing companies where welding is considered an important process. The cost of the manufactured products starts at 10,000 SEK, ending at several millions. The yearly production volumes ranges from less than 100 up to 20,000 welded parts.

The interview was based on semi-structured questions in accordance to Lantz [10]. The interview was performed by two different interviewers, recorded and documented. Two persons with thorough knowledge of welding were interviewed at each site. The data was compiled and analyzed to see differences and similarities between the companies.

\section{Empirical findings}

The empirical findings contains both the experimental results and the findings from the interview study.

\subsection{Results from the experimental evaluation}

Figure 5 shows results from the experimental evaluation. Scalings and offsets by least square minimization have been used. The solid line is nominal gap, whereas the thick dashed line shows the estimate from the arc voltage signal, and the thin dotted line shows the estimate from the fused camera image sequence. The root-mean-square deviation between the nominal gap and the estimated gap along the whole weld seam is $0.26 \mathrm{~mm}$ in the case of the estimate from the electrical signal and $0.28 \mathrm{~mm}$ in the case of the estimate from the fused image sequence.

Gap size and penetration depth is measured from images of etched cross cut welds showing the fused zone. Robust regression with bi-square weights in an iteratively reweighted least-squares algorithm has been used to fit a line to data [9].

The relation between the measured gap size $g$ and penetration $i$ is given in Fig. 6 as a line together with $95 \%$ 


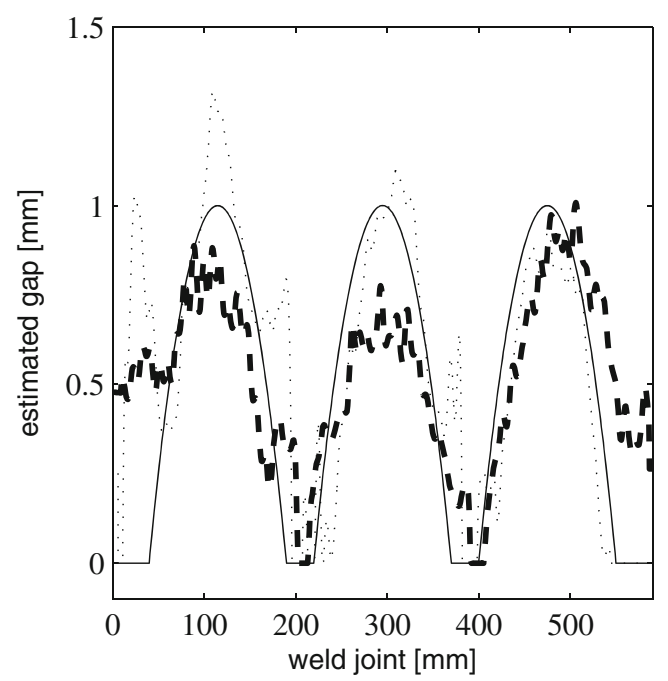

Fig. 5 Experimental result where the solid line is nominal gap whereas the estimate from the arc voltage is shown as a thick dashed line, and the camera estimate is shown as the thin dotted line

confidence bounds. A 1-mm gap size results in $50 \%$ increase in penetration depth relative to zero gap situations.

\subsection{Results from the interview studies}

All the three companies are currently focusing on postprocess inspection. Companies $\mathrm{B}$ and $\mathrm{C}$ are using radiography; company A is using ultrasonic testing. All are using visual inspection and penetrant testing. There is a difference when it comes to the main driver of checks performed. The inspections at company A are mainly driven by previous defects while the other two companies are mentioning customer demand. They are also experiencing a need of

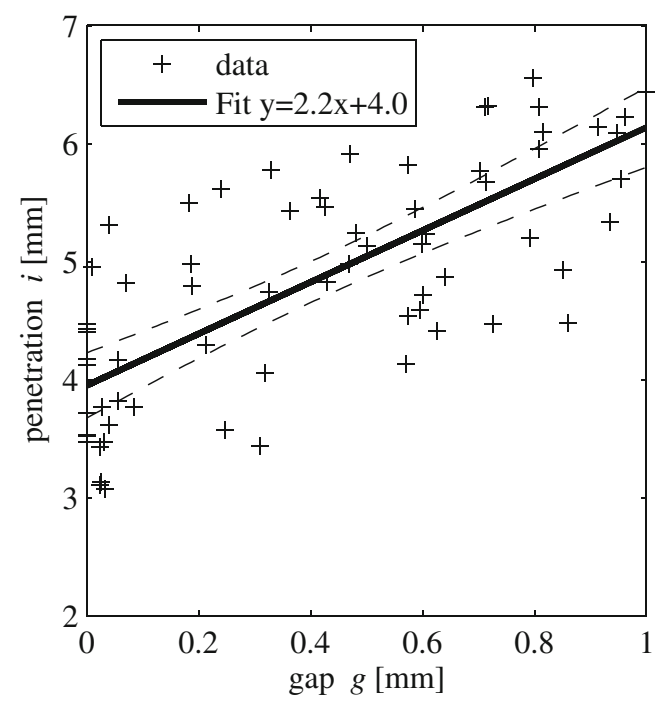

Fig. 6 The relation between the measured gap size and penetration depth inspection method when it comes to detecting lack of fusion. The company A sees a need to be able to detect non visible defects online. They are also mentioning the need for improved reliability as well as possibility for the operator to get information when any deviations occur. Only the company $\mathrm{C}$ had personnel dedicated for developing the inspection and audit process itself.

None of the three companies were using in-process monitoring but could see advantages by using it. The most common advantage stated was to use monitoring to control the process and to avoid defects. One company stated it should be used for root cause analysis but also to stabilize or stop the process.

The barriers restricting the companies from using inprocess monitoring is summarized in Fig. 7. One respondent answered that the technique for 'green lamp' does not exist but otherwise all obstacles identified by the respondents were non-technical issues. Competence was mentioned by all the three companies. The lack of common understanding and knowledge about available techniques are also connected to competence. Another area is the connection to financial figures. The company A states that the financial effect is unclear, which act as a barrier. The company $\mathrm{C}$ describes a problem to get the investment approved unless it is an explicit customer requirement.

\section{Discussion}

The research project has shown technical possibilities to monitor penetration depth during welding. Even though there are technical limitations, the interview study indicates that there are other areas acting as barriers for monitoring weld properties. The cost of defects in form of shallow penetration depth is not clear. There is an awareness of the cost of repair but the cost connected to risk of failures; extra attention within the organization etc. is not handled. In the investment process, there is mainly a financial language used, and a business case needs to be formulated where the investment is shown profitable.

There are pros and cons with different monitoring techniques available. Which solution is preferable depends on e.g. reachability for the particular product. Electrical

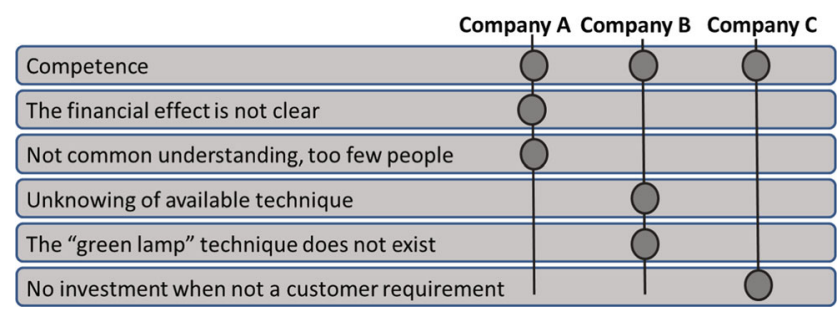

Fig. 7 Barriers restricting the use of monitoring 
sensing is according to Simpson [18] a robust technique which is not affected by the harsh industrial welding environment but can be difficult to interpret. The root-meansquare deviation between the nominal gap and the estimated gap size from the performed experiments was 0.26 and $0.28 \mathrm{~mm}$ for arc voltage signal and fused camera image sequence, respectively. The accuracy in the estimate needs to be improved compared to what was achieved. Especially when it comes to the result of the cameras, several improvements have been identified e.g. having an optimized orientation and standardized calibration of the camera for measuring only the gap size. The measurement deviation between the methods investigated is in the same range. However, the improvement potential is regarded as better for the cameras compared to the electrical signals.

Considering the organizational issues, it can make sense to start monitoring using electrical signals before using cameras even though the result might include more measurement noise. The reasons are several. The main reason would be to let the organization get used to the idea of monitoring and getting the structure and work methods in place without having to invest in more expensive technology. That increases the knowledge about monitoring and makes it easier to formulate a business case for a more advanced system (if shown necessary). Having that said, it can sometimes be easier for organizations to buy equipment instead of changing organizational issues, since the process and responsibilities for doing so are much clearer.

An important issue to consider is how the property or defect is defined. Simpson [19] and Schreiber [17] are using reference welds for training the system of distinguishing between an approved and disapproved weld. Certainly, there are gray areas when this approach fails to distinguish the samples. This approach also requires a human pre-judgment which can deviate between operators.

The difference in answers from the companies when it comes to the main driver of checks performed could originate from the differences in business. Within the construction equipment, it is not as common to get customer demands about what inspection method to use as it is in energy or aerospace business.

The differences in lacking inspection method can probably be emanated from the disadvantages with the current method used. The construction equipment company did not use radiography and hence did not see the drawbacks from that method. Instead, they saw a need to detect small weld toe radii, which is included in their weld standard and not the others'.

Welding in itself is a complex process, influenced by numerous parameters. Simpson [18] states that reproducible welding is vital for sensitive fault detection and that one has the bonus of better fault detection capability when improving the welding processes. However, this approach shows a strange view of who the customer is in the process.
The monitoring system should help the welding process to improve, not the opposite. It is necessary to keep in mind for whose sake the monitoring should be done. Different parts of the organization need different information about the penetration depth. That also needs to be well considered when designing a monitoring system. Previous research has been merely technical. However, such a focus misses out a large part of the actual problem, that is, what information the organization actually needs. It is also of outmost importance to define how this new information should be used and by whom. The designers need information about the manufacturing system's ability to perform in order to support them in the decision to change the design towards lighter products, by thinner plates and smaller weld sizes. The information needed in that case is probably showing the variation over time and the overall risk of any deviations. The operator on the other hand might instead need an instant warning when there is a risk of lack of penetration on a particular weld. That information needs to be instant and very precise for him or her to act.

The practical implications if these barriers are overcome are significant. By assuring the penetration depth, the company can gain in two areas: defect parts with too shallow penetration are avoided and the over-processing resulting in large throat thickness due to safety margins can be prevented.

\section{Conclusions and future research}

The research conducted examines why robust in-process monitoring and adaptive control are not fully implemented in the welding industry. Weld penetration depth was chosen as quality property to monitor because of its importance for the welding industry. The research gives two important conclusions:

- It is possible to monitor penetration during welding by using arc voltage measurements, CMOS vision and infrared cameras. There are still technical issues to be further researched to improve disturbance rejection but the result is very promising.

- The interview study indicates that soft issues, like competence and financial aspects, are as critical as the technical issues but are more difficult to handle compared to buying equipment.

This research result is of theoretical relevance since it guides future research towards necessary issues to solve in order for the industry to be able to use the advances fully. If a working monitoring could be acquired and implemented, the company could gain the benefits of reducing safety margins, improve productivity and enable a more lightweight structure design. 
The conducted research has included weld penetration depth in fillet welds produced by GMAW. The interviews have been performed at three large welding companies in Sweden. Future research could build on these results and investigate if the same applies for other types of welding, company sizes and geographical location.

The interviews indicated a deficiency in how to express cost of poor weld quality. That played an important role in the investment process, since the business case should be profitable. Therefore, it would be of great advantage to create a model including other aspects than only cost of repairs. Also, technical aspects could be further developed, e.g. automated monitoring solutions giving the operator an OK/not OK signal.

The robustness of the system has to be sufficient both physically and in terms of data interpretation which also calls for further research. A future development in this area is to be able to not only monitor but also control the process. By using information obtained in real time, parameters could be changed online to achieve the desired properties. Such a development requires more research about the influencing parameters.

Acknowledgments The research work being the base for this paper has been partly funded by The Knowledge Foundation. A great contribution has been made by the staff at Siemens and GKN in Trollhättan as well as at the Volvo CE Arvika plant. A special thanks to Xiao Xiao Zhang for preparing the test samples and Anna-Karin Christiansson for proof reading and input to the text.

Open Access This article is distributed under the terms of the Creative Commons Attribution 4.0 International License (http:// creativecommons.org/licenses/by/4.0/), which permits unrestricted use, distribution, and reproduction in any medium, provided you give appropriate credit to the original author(s) and the source, provide a link to the Creative Commons license, and indicate if changes were made.

\section{References}

1. Al-Habaibeh A, Parkin R (2003) An autonomous low-cost infrared system for the on-line monitoring of manufacturing processes using novelty detection. Int $\mathrm{J}$ Adv Manuf Technol 22:249258

2. Cayo EH, Alfaro SCA (2009) A non-intrusive GMA welding process quality monitoring system using acoustic sensing. Sensors 9:7150-7166

3. Chandrasekhar N, Vasudevan M, Bhaduri AK, Jayakumar T (2015) Intelligent modeling for estimating weld bead width and depth of penetration from infra-red thermal images of the weld pool. J Intell Manuf 26:59-71

4. Dahle T, Olsson KE, Samuelsson J (1999) Fatigue design optimisation of welded box beams subjected to combined bending and torsion. In: Solin GmaJ (ed) European Structural Integrity Society, Fatigue Design and Reliability, vol 23. Elsevier
5. Deshmukh AR, Venkatachalam G, Divekar H, Saraf MR (2014) Effect of weld penetration on fatigue life. Procedia Eng 97:783-789

6. Ericson Öberg A, Johansson M, Holm EJ, Hammersberg P, Svensson LE (2012) The influence of correct transfer of weld information on production cost

7. Fidali M, Jamrozik W (2013) Diagnostic method of welding process based on fused infrared and vision images. Infrared Phys Technol 61:241-253

8. Hammersberg P, Olsson H (2013) Proactive control of weld dimensions in robotised MAG welding

9. Holland PW, Welsch RE (1977) Robust regression using iteratively reweighted least-squares. Communications in statistics: theory and methods A6:813-827

10. Lantz A (2007) Intervjumetodik, 2nd edn. Studentlitteratur, Lund

11. Li Y, Li YF, Wang QL, Xu D, Tan M (2010) Measurement and defect detection of the weld bead based on online vision inspection. IEEE Trans Instrum Meas 59:1841-1849

12. Lin T, Chen HB, Li WH, Chen SB (2009) Intelligent methodology for sensing, modeling, and control of weld penetration in robotic welding system. Ind Robot 36(6):585-593

13. Lv N, Zhong J, Chen H, Lin T, Chen S (2014) Real-time control of welding penetration during robotic GTAW dynamical process by audio sensing of arc length. Int J Adv ManufTechnol 74:235-249

14. Metwalli MR, Nasr AH, Allah OSF, El-Rabaie S (2009) Image fusion based on principal component analysis and high-pass filter. In: International Conference on Computer Engineering Systems, 2009. ICCES 2009, Cairo, pp 63-70. doi: 10.1109/ ICCES.2009.5383308

15. Öberg A, Hammersberg P, Svensson LE (2012) Selection of evaluation methods for new weld demands: pitfalls and possible solutions. Durban, South Africa

16. Raj B, Subramanian CV, Jayakumar T (2000) Non-destructive testing of welds. Alpha Science International Ltd, India

17. Schreiber D, Cambrini L, Biber J, Sardy B (2008) Online visual quality inspection for weld seams. Int J Adv Manuf Technol 42(56):497-504

18. Simpson SW (2007) Signature images for arc welding fault detection. Sci Technol Weld Join 12(6):481-486

19. Simpson SW (2008) Fault identification in gas metal arc welding with signature images. Sci Technol Weld Join 13(1):87-96

20. Simpson SW (2008) Through arc sensing in gas metal arc welding with signature images. Sci Technol Weld Join 13:80-86

21. St. Wglowski M (2009) Henry Granjon Prize Competition 2007 winner, Category A "Joining and Fabrication Technology": utilization of the arc light emission emitted during TIG welding to monitoring this process. Welding in the World 53:R2-R12

22. Sumesh A, Rameshkumar K, Mohandas K, Babu RS (2015) Use of machine learning algorithms for weld quality monitoring using acoustic signature. Procedia Computer Science 50:316-322

23. Swedish Standard (2004) SS-EN ISO 5817 Welding-fusionwelded joints in steel, quality levels for imperfections. Tech. rep.

24. Volvo Group (2011) STD 181-0004 fusion welding-weld classes and requirements life optimized welded structures steel, thickness $3 \mathrm{~mm}$. Tech. rep., Volvo Group

25. Wang Z (2014) Monitoring of GMAW Weld pool from the reflected laser lines for real-time control. IEEE Trans Ind Inform 10(4):2073-2083

26. Weman K, Linde'n G (2006) MIG welding guide. CRC Press, Boca Raton

27. Zhiyong L, Srivatsan TS, Hongzhi Z, Xiaocheng Y, Yong G (2011) On the use of arc radiation to detect the quality of gas metal arc welds. Mater Manuf Process 26(7):933-941 